\title{
Karbon Katı Asit Katalizör ile Atık Biyokütle Kaynaklarından 5-Hidroksimetilfurfural Eldesi
}

\author{
Burçak KAYA ÖZSEL ${ }^{* 1}$ (D) \\ ${ }^{1}$ Bursa Teknik Üniversitesi, Mühendislik ve Doğa Bilimleri Fakültesi, Kimya Bölümü, 16310, Bursa, Türkiye
}

(Alınış / Received: 12.11.2019, Kabul / Accepted: 18.02.2020, Online Yayınlanma / Published Online: 20.04.2020)

\author{
Anahtar Kelimeler \\ Biyokütle, \\ Karbon katı asit katalizör, \\ 5-Hidroksimetilfurfural
}

\begin{abstract}
Özet: Bu çalışmada, buğday samanı biyokütlesinden hidrotermal karbonizasyon yöntemi ile biyokütle türevli karbon katı asit katalizör (BH250S) elde edilmiş, katalizörün atık biyokütle kaynaklarından 5-Hidroksimetilfurfural (5-HMF) sentezi aktivitesi belirlenen optiumum koşullarda sulu reaksiyon ortamında ticari katalizör (Amberlyst-15) ile kıyaslanmıştır. Katalizörün karakterizasyon çalışması elemental analiz, BET, SEM ve XRD analizleri yapılarak tamamlanmıştır. Atık biyokütle olarak mısır samanı, hav, linter, model bileşik olarak ise mikrokristalin selüloz kullanılmış, 5-HMF'ye dönüşüm verimleri kıyaslandığında mısır samanı, hav ve mikrokristalin selüloz için BH250S katalizörünün aktivitesinin ticari katalizörden daha yüksek olduğu gözlenmiştir. Gram biyokütle başına en yüksek 5HMF miktarı 14,2 mg olarak BH250S katalizörü ile model bileşik mikrokristalin selülozun dönüşümünden elde edilirken, ekonomik değeri olmayan atık biyokütle havdan elde edilen değer 12,5 mg' dır. Çalışma sonucunda ekonomik değeri düşük atık lignoselülozik/selülozik biyokütle materyalleri değerlendirilmiş, çevreye dost, sürdürülebilir ve ucuz katalitik yolla 5-HMF eldesi sağlanmıștır.
\end{abstract}

\section{Synthesis of 5-Hydroxymethylfurfural from Waste Biomass Feedstocks Using Carbon Solid Acid Catalyst}

\section{Keywords}

Biomass,

Carbon solid acid catalyst,

5-Hydroxymethylfurfural

\begin{abstract}
In this study biomass derived carbon solid acid catalyst (BH250S) was obtained by hydrothermal carbonization method from wheat straw, 5-HMF synthesis activity of the catalyst from waste biomass sources in optimum conditions was determined and compared with commercial catalyst (Amberlyst15). Characterization of the catalyst was completed by elemental analysis, BET, SEM and XRD analysis. Corn straw, fluff and linter were used as waste biomass, microcrystalline cellulose was used as a model compound and conversion efficiency to 5-HMF was found to be higher than that of commercial catalyst for BH250S for corn straw, fluff and microcrystalline cellulose. The highest amount of 5 -HMF per gram biomass was obtained from the conversion of model compound microcrystalline cellulose with BH250S catalyst was $14.2 \mathrm{mg}$ while the value obtained from economically non-useful waste fluff was $12.5 \mathrm{mg}$. As a result of this study, waste lignocellulosic/cellulosic biomass materials with low economic value were evaluated and 5-HMF was obtained by a eco-friendly, sustainable and cheap catalytic method.
\end{abstract}

\section{Giriş}

Son yıllarda fosil kaynakların tükenmek üzere oluşu ve çevreye verdiği zararlar nedeniyle biyokütleden yakıt ve çeşitli değerli kimyasalların eldesine ilişkin prosesler son derece önem kazanmıștır. Biyokütle kaynakları içerisinde lignoselülozik/selülozik biyokütle olarak adlandırdığımız (tarımsal atıklar, enerji bitkileri, orman atıkları vb. kaynaklar) grup bol bulunma ve çevre dostu olma özelliği, gıda maddesi olarak insanlar tarafından tüketilmeyenler sınıfına girmeleri, atmosferdeki sera gazı artışına katkıda bulunmayışları gibi özelliklerinden dolayı enerji ve değerli kimyasal ürün eldesi alanında değerlendirilme açısından oldukça cazip görünmektedir. 
'Uyuyan Dev' olarak adlandırılan 5hidroksimetilfurfural (5-HMF) biyokütle türevli değerli kimyasallardan biri olup, monosakkarit (fruktoz, glukoz) ve disakaritlerin (sukroz, sellobioz) katalizörlü ortamda hidroliz, izomerasyon ve dehidrasyonu (Şekil 1) ile elde edilebilmekte, birçok önemli yeni nesil biyopolimer ve biyoyakıt eldesi için öncü bileşik olarak kullanılmaktadır [1].

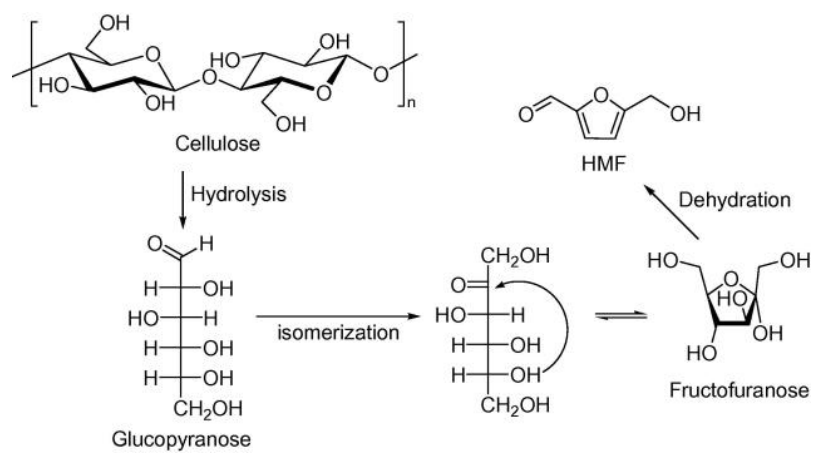

Şekil 1. Selülozik yapının 5-HMF’ye dönüşümü [2].

Örneğin; 5-hidroksimetilfurfuralın (5-HMF) oksitlenmesi sonucu elde edilen 2,5furandikarboksilik asit (FDCA), etilen glikol ile reaksiyona sokularak polietilen tereftalata (PET) alternatif yeni nesil bir biyopolimer olan polietilen furanoatın (PEF) sentezinde kullanılmaktadır. PEF, günümüzde yaygın olarak kullanılan petrol bazlı ambalaj malzemelerine kiyasla üstün performans özelliklerine sahip, \%100 geri dönüştürülebilir, tamamen yenilenebilir biyokütle kaynaklarından elde edilen bitki-bazlı bir plastiktir [3]. Etil levulinat (EL) ise 5-hidroksimetilfurfuralın (5-HMF) asit katalizli hidrasyonu ile oluşan levulinik asidin esterleşmesi ile elde edilen ve günümüzde dizel yakıta \%5’e kadar katkı maddesi olarak eklenen bir kimyasaldır. Dizel yakıtlara eklendiğinde temiz yanma özelliği, kayganlık ve parlama noktası kararlılığı kazandırır ve viskoziteyi arttırır [4]. 5-hidroksimetilfurfuralın (5-HMF) asit katalizli hidrasyonu ile oluşan levulinik asidin hidrojenasyonu ile elde edilen gamma-valerolakton (GVL) ise hem yakıt katkısı hem de yeni nesil çevreci çözücü olarak kullanılabilen ve metiltetrahidrofuran, 1,4pentandiol vb. birçok farklı kimyasalın sentezi için kullanılabilen öncü bir bileşiktir [5].

5-hidroksimetilfurfuralın yapısındaki hidroksil ve aldehit fonsiyonel grupları ve furan halkasının varlı̆̆ı daha büyük ve önemli moleküllerin sentezi açısından bu yapıyı avantajlı hale getirmektedir. Karbonhidratların 5-HMF dönüşümünü sağlamaya yönelik çalışmalarda kullanılan katalizörler ve biyokütle çeşidi verimi etkileyen parametrelerin başında gelir. Dönüşüm proseslerinde reaksiyon ortamından kolay ayrımı, çevre dostu olması ve tekrar tekrar kullanılabilirliği açısından heterojen katı asit katalizörler daha çok tercih edilmekte ve son yıllarda özellikle biyokütle türevli karbon-bazlı katı asit katalizörlerin 5-HMF dönüşüm prosesinde kullanımı ön plana çıkmaktadır. Karbon katı asit katalizörler literatürde genelikle selüloz, glikoz vb. saf bileşiklerden yüksek sıcaklıkta yarı karbonizasyon sonrası sülfolama metodu ile elde edilmektedir [6,7].

$\mathrm{Bu}$ çalışmada ise sert karbonizasyon koşulları ve zararlı gazların emisyonu nedeniyle çok çevreci ve sürdürülebilir olmayan bu karbonizasyon prosesi yerine, yine ılımlı sıcaklıkta gerçekleştirilen hidrotermal karbonizasyon uygulanarak gerçek biyokütle olan buğday samanından biyokütle türevli sülfolanmış karbon katı asit katalizör (BH250S) elde edilmiș, katalizörün aktivitesi belirlenen optiumum koşullarda sulu reaksiyon ortamında ticari katalizör (Amberlyst-15) ile kıyaslanmıștır. Atık ve dolayısıyla ucuz lignoselülozik biyokütle kaynağı olarak buğday ve mısır samanı; selülozik biyokütle olarak ise linter ve hav kullanılmıştır. Havlar tekstilde pamuklu kumaş ön terbiye ișlemleri sırasında atık olarak ortaya çıkan, ekonomik değeri olmayan selüloz esashı kısa liflerdir. Selüloz içeriği yüksek linter ise pamuk bitkisini ișleyen fabrikalarda (çırçır, yağ fabrikaları vb.) pamuk tohumundan işlenmeyen yan ürün olarak elde edilmektedir. Mısır ve buğday samanı ise dünyada en bol bulunan ve tarım atığ olarak değerlendirilebilen yenilenebilir biyokütle kaynaklarının başında gelmektedir. Ülkemizin bir tarım ülkesi olduğu düşünüldügünde bu çalışma endüstriyel ve tarımsal bu ve benzeri katı atıkların ucuz hammadde olarak değerlendirilmesi ve geri dönüşümüne de olanak sağlayacaktır.

\section{Materyal ve Metot}

\subsection{Materyal}

Çalışmada kullanılan buğday samanı ve mısır samanı Adana'daki lokal satış noktalarından; linter ER-MO Pamuk İhracat, İthalat Tic. Ltd. Şti. (Adana) firmasından; hav ise Bursa'daki çeşitli tekstil firmalarından temin edilmiştir. Biyokütle materyallerinin nem ve kül, selüloz, hemiselüloz ve lignin içerikleri belirlenmiştir. Saf mikrokristalin selüloz dönüşüm deneylerinde gerçek biyokütleler ile karșılaștırma amacıyla kullanılmıștır.

\subsection{Biyokütle türevli karbon bazlı katı asit katalizörün hazırlanması}

Biyokütle türevli karbon bazlı sülfolanmış katı asit katalizörlerin hazırlanmasında başlangıç biyokütle materyali olarak lignoselülozik karakterli buğday samanı seçilmiştir. Yöntemde, belirli miktarda buğday samanı deiyonize su ile birlikte reaktöre konmuș, $250^{\circ} \mathrm{C}^{\prime}$ de 2 saat hidrotermal otohidroliz ile yarı-karbonizasyona uğratılmıştır. Elde edilen yarıkarbonize yapıdan $1 \mathrm{~g}$ alınarak $20 \mathrm{ml}$ derişik sülfürik asitle $150{ }^{\circ} \mathrm{C}$ de 16 saat $\mathrm{N}_{2}$ atmosferinde sülfolanmıștır. Buz banyosu ile oda sıcaklığına soğutulan karışım 1000 ml'ye saf su ile seyreltilip vakumlu süzme düzeneği ile süzülmüștür. Nötralizasyon tamamlanıncaya ve fazla sülfat iyonu 
kalmayıncaya kadar yıkama işlemi uygulanmıştır. Etüvde bir gece $105 \pm 2{ }^{\circ} \mathrm{C}$ 'de bekletilerek kurutulan karbon yapılar kullanıma hazır hale getirilmiștir. Üretilen katı asit katalizör BH250S (B:buğday samanı, H:hidrotermal yarı-karbonizasyon, S:sülfolanmış) şeklinde kodlanmıştır.

\subsection{Katı asit katalizörün karakterizasyonu}

Katalizörün elementel analizi (C,H,N,S) LECO 628 CHNS cihazı ile gerçekleştirilmiştir. XRD analizleri, PANALYTICAL/Empyrean X-Işını Difraktometresi ile $3^{\circ} / \mathrm{dk}$ tarama hızında ve $2 \theta=5-90^{\circ}$ aralığında tarama yapılarak elde edilmiştir. Toplam yüzey alanı (BET) ve gözenek boyutu analizi için Micromeritics TriStar II cihazı kullanılmıştır. Katalizörün morfolojik özellikleri ise Zeiss Supra 40VP model taramalı elektron mikroskobunda incelenmiştir.

\subsection{Tek-basamaklı katalitik dönüşüm deneyleri ve çözelti analizleri}

Tek-basamaklı biyokütle dönüşümlerinde $0,5 \mathrm{~g}$ biyokütle, 0,25 g katalizör ve $25 \mathrm{ml}$ deiyonize su batch tipi reaktöre konulmuş, reaktör azot gazı ile purge edilmiş ve $200{ }^{\circ} \mathrm{C}^{\prime}$ de 1 saat sürede katalitik reaksiyonlar gerçekleştirilmiştir. Reaksiyon süresi sonunda buz banyosu ile hızlı soğutma uygulanmış ve elde edilen çözelti HLPC (sıvı kromatografisi) analizleri için 2 ml'ye deriştirilerek filtreden geçirilmiştir. 5-HMF miktarlarının tayini ACE C18 kolonda (250 x 4,6 mm) analitik modda, UV dedektörü ile $280 \mathrm{~nm}$ dalga boyunda gerçekleştirilmiştir. Analiz, 0,5 ml/dk akış hızı ile 25 ${ }^{\circ} \mathrm{C}$ sicaklıkta, \%0,001 $\mathrm{H}_{3} \mathrm{PO}_{4}$ çözeltisi ve saf $\mathrm{MeOH}$ mobil fazları kullanılarak gradient olarak yapılmıştır. Glikoz miktarları ise InertSustain- $\mathrm{NH}_{2}$ kolonda $(250 \mathrm{x}$ 4,6 mm), refraktif indeks (RI) dedektör ile, $35{ }^{\circ} \mathrm{C}$ sıcaklık, $1 \mathrm{ml} / \mathrm{dk}$ akış hızı, asetonitril/su (3:1, v/v) mobil fazı ile gerçekleștirilmiștir. Analizlerde kantitatif tayin için kalibrasyon eğrilerinin oluşturulmasında 5-HMF ve glikoz standartları kullanılmıştır. Tek-basamaklı dönüşüm reaksiyonlarından sonra başlangıçtaki katı miktarı ve kalan katı biyokütle miktarlarından yola çıkılarak hidroliz verimleri hesaplanmıştır.

\section{Bulgular}

\subsection{Biyokütle materyallerinin karakterizasyon analizleri}

Çalışmada kullanılan biyokütle materyallerinin nem yüzdesi ASTM 1983 D-2016-74, kül yüzdesi ise ASTM 1983 D-1102-84 [8] yöntemi kullanarak belirlenmiştir. Lignin oranının belirlenmesi için ASTM 2009 E-1721-01 [9] yöntemi kullanılmış, selüloz içeriği monoetanolamin metodu [10] ile hemiselüloz içeriği ise Sun ve Tomkinson tarafindan geliştirilen hemiselüloz izolasyon yöntemi [11] ile belirlenmiştir. Hesaplanan sonuçlar Tablo 1' de verilmiştir. Lignoselülozik biyokütleler olan buğday ve mısır samanının kül ve nem içerikleri birbirine benzer sonuçlar verirken, selülozik biyokütleler hav ve linterin kül ve nem içeriklerinin nispeten daha düşük olduğu görülmektedir. Linter ve havin kül oranının düşük olması, kül içeriğindeki inorganik elementlerin katalitik dönüşüm basamağında çar oluşumunu azaltıcı yöndeki etkileri düșünüldügünde dezavantaj olarak düşünülebilir. Biyokütleden farklı değerli kimyasalların elde edildiği proseslerde lignin, selüloz ve hemiselüloz oranları önemlidir. Selüloz içeriğinin daha fazla olması nedeniyle linter etkin hidrolizi halinde misır samanına göre 5-HMF'ye dönüşüm potansiyeli daha yüksek bir biyokütle kaynağı olarak düşünülebilir. Ayrıca yüksek sıcaklık ve katalizör varlığında gerçekleşecek dönüşüm reaksiyonları düşünüldüğünde lignin gibi aromatik ve karmaşık bir yapıyı içermemesi de başka bir avantajdır.

Tablo 1. Biyokütlelerin nem, kül, lignin, selüloz ve hemiselüloz içerikleri

\begin{tabular}{|c|c|c|c|c|c|}
\hline Biyokütle & $\begin{array}{c}\text { Nem } \\
\text { (\%) }\end{array}$ & $\begin{array}{c}\text { Kül } \\
\mathbf{( \% )}\end{array}$ & $\begin{array}{c}\text { Selüloz } \\
(\mathbf{\% )}\end{array}$ & $\begin{array}{c}\text { Lignin } \\
\mathbf{( \% )}\end{array}$ & $\begin{array}{c}\text { Hemiselüloz } \\
(\mathbf{\% )}\end{array}$ \\
\hline Mısır & 8,10 & 8,06 & 49,96 & 15,09 & 15,30 \\
Samanı & $\pm 0,1$ & $\pm 2,0$ & $\pm 0,6$ & $\pm 0,1$ & $\pm 1,1$ \\
\hline Buğday & 6,33 & 6,87 & 48,13 & 19,97 & 24,72 \\
Samanı & $\pm 0,2$ & $\pm 1,0$ & $\pm 0,1$ & $\pm 1,0$ & $\pm 2,6$ \\
\hline \multirow{2}{*}{ Linter } & 4,54 & 2,66 & 82,20 & 3,00 & 4,19 \\
& $\pm 0,3$ & $\pm 0,4$ & $\pm 0,8$ & $\pm 0,2$ & $\pm 0,4$ \\
\hline \multirow{2}{*}{ Hav } & 4,80 & 1,10 & 55,11 & 2,30 & 21,01 \\
& $\pm 0,1$ & $\pm 0,2$ & $\pm 1,3$ & $\pm 0,6$ & $\pm 0,1$ \\
\hline
\end{tabular}

\subsection{Biyokütle türevli katı asit katalizörün karakterizasyonu}

Hidrotermal yarl-karbonizasyon ve sülfolama işlemi ile buğday samanından elde edilen BH250S katı asit katalizörünün yüzey alanı, gözenek boyut dağılım analizi ve elementel analiz sonuçları Tablo 2' de verilmiştir.

Tablo 2. Katı asit katalizör (BH250S) gözenek boyut dağılımı ve elementel içeriği

\begin{tabular}{|c|c|c|c|c|c|c|}
\hline $\begin{array}{c}\text { Gözenek } \\
\text { hacmi } \\
\left.\mathbf{( c m}^{3} \mathbf{g} \mathbf{g}\right)\end{array}$ & $\begin{array}{c}\text { Gözenek } \\
\text { boyutu } \\
\text { (nm) }\end{array}$ & $\begin{array}{c}\mathbf{S O}_{3} \mathbf{H} \\
(\mathbf{m m o l} / \mathbf{g})\end{array}$ & $\begin{array}{c}\mathbf{S} \\
\mathbf{( \% )}\end{array}$ & $\begin{array}{c}\mathbf{C} \\
\mathbf{( \% )}\end{array}$ & $\begin{array}{c}\mathbf{N} \\
\mathbf{( \% )}\end{array}$ & $\begin{array}{c}\mathbf{H} \\
\mathbf{( \% )}\end{array}$ \\
\hline 0,002 & 5,52 & 1,70 & 5,5 & 50,5 & 0,5 & 3,4 \\
\hline
\end{tabular}

$\mathrm{SO}_{3} \mathrm{H}, \mathrm{COOH}$, ve $\mathrm{OH}$ grupları taşıyan polisiklik aromatik karbon yüzeylerden oluşmuş bir yapıda olan karbon katalizörün yüzey alanının oldukça küçük olduğu görülmektedir. Benzer bir çalışmada Gan ve arkadaşları [12] lignini $240{ }^{\circ} \mathrm{C}$ 'de 10 saat süre ile hidrotermal yarı-karbonizasyona uğratıp ardından sülfürik asit ile sülfolama işlemine tabii tutmuş ve yüzey alanı $0,8 \mathrm{~m}^{2} / \mathrm{g}$ olan katı asit karbon katalizör elde etmişlerdir. Katalizörü selülozun hidrolizinde kullanmış ve yüksek katalitik aktivite gösterdiğini kaydetmişlerdir. Suganuma ve arkadaşları [13] ise mikrokristalin selülozdan azot atmosferinde 450 ${ }^{\circ} \mathrm{C}$ 'de termal yarı-karbonizasyon sonrası sülfolama işlemi ile aktivitesi yüksek karbon katı asit katalizör elde etmiş ve yüzey alanını 2,0 $\mathrm{m}^{2} / \mathrm{g}$ olarak 
belirlemişlerdir. Dolayısıyla katalizörün yüzey alanının küçük olması literatürden de beklenen bir sonuçtur. Katalizörün yüzey asidik grup $\left(-\mathrm{SO}_{3} \mathrm{H}\right)$ miktarı elementel analiz sonuçları kullanılarak 1,70 mmol/g olarak hesaplanmıştır. Aynı zamanda elementel analiz sonuçlarına göre sülfolama sonrası, ham biyokütle materyali ile klyaslandığında BH250S katalizörünün S içeriği \% 0,4 'ten $\% \quad 5,5$ değerine çlkmıştır. $\mathrm{Bu}$ durum aromatik karbon yapıya sülfonasyon ile - $\mathrm{SO}_{3} \mathrm{H}$ gruplarının başarılı bir şekilde bağlandığını göstermektedir.

Biyokütle türevli karbon bazlı sülfolanmış katı asit katalizörün XRD analiz sonucu Şekil 2' de verilmiştir. Spektrumda $2 \theta=25^{\circ}$ civarında gözlenen (002) düzleminden kaynaklanan pik rasgele yerleşmiş amorf karbon tabakaların varlığını işaret etmektedir [14].

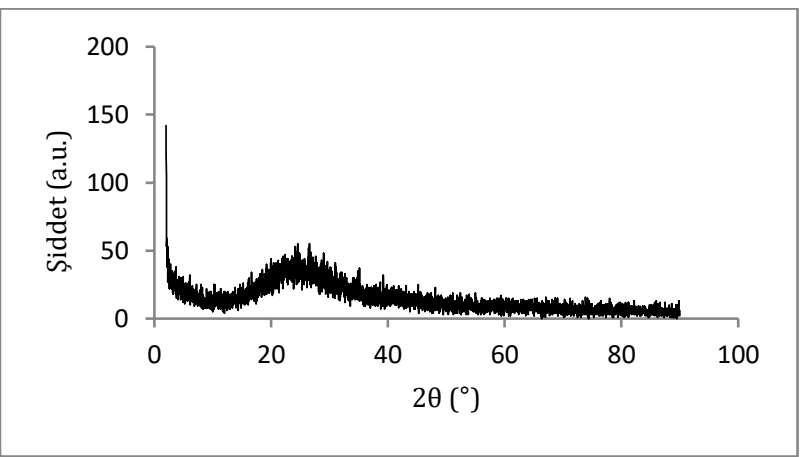

Şekil 2. BH250S katalizörünün XRD spektrumu

Şekil 3' deki SEM görüntülerinde yarı-karbonize olmuş biyokütle yapısı ve konsantre sülfürik asit ile sülfolama işleminin etkisi gözlenmektedir.

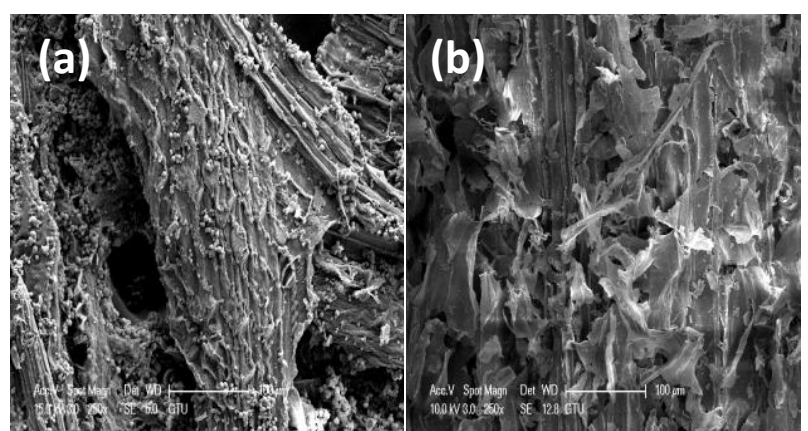

Şekil 3. (a) $250^{\circ} \mathrm{C}$ hidrotermal yarı-karbonize (b) $250^{\circ} \mathrm{C}$ hidrotermal yarı-karbonizasyon sonrası sülfolanmış biyokütle yapısının SEM görüntüleri

Hidrotermal yarı-karbonizasyon işlemi sonrası yüzeyde oluşan damlacıklar sulu ortam ve yüksek sıcaklıkta hidrolize olmaya başlayan lignoselülozik yapıdan kaynaklı yüzeyde lignin birikimini işaret etmektedir [15]. Ayrıca sert sülfolama işlemi görüldüğü gibi gözenek yapılarını değiștirmekte ve yapının parçalandığı görülmektedir.

\subsection{Tek basamakta biyokütle dönüşümü ile 5- HMF eldesi}

Farklı biyokütle materyalleri ile tek basamakta gerçekleştirilen dönüşüm deneylerinde katalizör varlığında hidroliz oranlarının arttığı gözlenmektedir (Şekil 4). Amberlyst-15, BH250S katalizörüne kıyasla hidroliz verimini arttırmada daha etkili olmuş, en yüksek hidroliz oranına \%76,2 ile model bileșik olan selülozda ulaşılmıştır. BH250S katalizörü ise selülozun hidroliz verimini katalizörsüz denemeye kıyasla \%36,2 oranda arttırmaktadır.

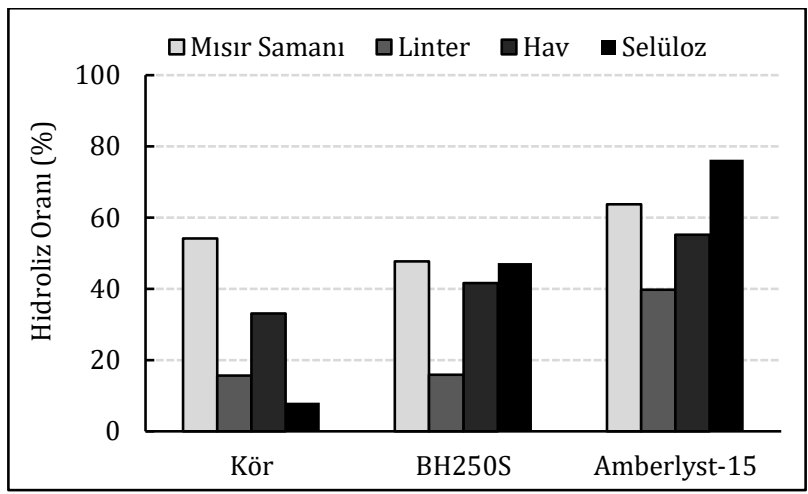

Şekil 4. Dönüşüm deneyleri sonrası farklı biyokütle türleri için hidroliz verimlerinin kıyaslaması

Gerçek biyokütleler içinde ise lignoselülozik biyokütle olan mısır samanı en fazla hidroliz olan yapıdır, hav ve linter onu takip etmektedir. Görüldüğü gibi katalizörlerin farklı biyokütleler üzerinde hidroliz etkileri biyokütle ve katalizörün yapısına bağlı olarak farklılaşabilmektedir. Yüksek kristaliniteye sahip rijit yapılı linteri katalitik olarak parçalamak bu nedenle diğer biyokütlelere göre daha zor olmuştur.

Biyokütlelerin 5-HMF'ye dönüşüm verimleri kıyaslandığında mısır samanı, hav ve mikrokristalin selüloz için laboratuvar ortamında elde edilen BH250S katalizörünün aktivitesinin ticari katalizör Amberlyst-15'in önüne geçtiği gözlenmiştir (Şekil 5). BH250S katalizörü varlığında yapılan deneylerde elde edilen 5-HMF miktarları katalizörsüz dönüşüm deneylerine kıyasla misır samanı, hav, linter ve mikrokristalin selüloz biyokütleleri için sırasıyla 2,8, 4,2, 11,5 ve 2,7 katına çıkmaktadır. Gram biyokütle başına en yüksek 5-HMF miktarı (14,2 mg) BH250S katalizörü ile model bileșik mikrokristalin selülozun dönüșümünden elde edilirken, tamamen atık bir biyokütle olan havdan elde edilen değer $(12,5 \mathrm{mg})$ ise ona oldukça yakındır. BH250S katalizörünün yapısındaki - $\mathrm{COOH}$ grupları asiditeyi arttırırken, $-\mathrm{OH}$ grupları ise $\beta$-1,4-glukandaki glikozit bağları ile hidrojen bağı oluşturarak etkileşir ve bu durum zincirdeki glikozit bağların diğer asidik bölgelerle etkileşimini arttırır. $\mathrm{Bu}$ özellik 5-HMF verimini arttırıcı yönde etki etmektedir [16]. 


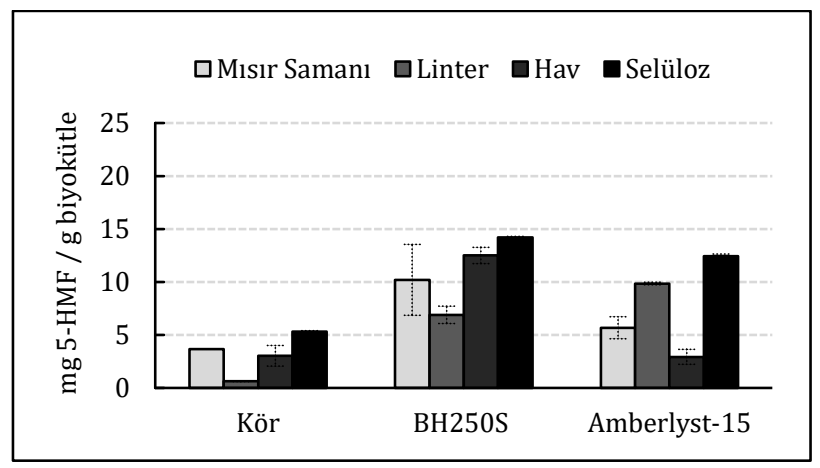

Şekil 5. Dönüşüm deneyleri sonrası elde edilen 5-HMF miktarlarının kıyaslaması

Şekil 6' de görüldüğü üzere katalizörlü dönüșüm deneylerinden reaksiyon sonrası ortamda bulunan glikoz miktarı daha fazla olmaktadır. Reaksiyon ortamında asidik karakterli bu katalizörler çözünen küçük şeker moleküllerini dönüştürmede etkili olurken, bir yandan da biyokütle materyallerinin etkin hidrolizini sürdürmektedir. Bu hidroliz etkisi her zaman glikoza kadar parçalanma şeklinde değil, daha büyük yapılı şeker moleküllerine (disakkaritler, polisakkaritler, vb.) parçalanma şeklinde de olabilir. Bu durum ticari Amberlyst-15 katalizörünün hidroliz etkisinin yüksek olmasına karşın 5-HMF dönüşüm etkinliğinin düşük olmasının sebeplerindendir.

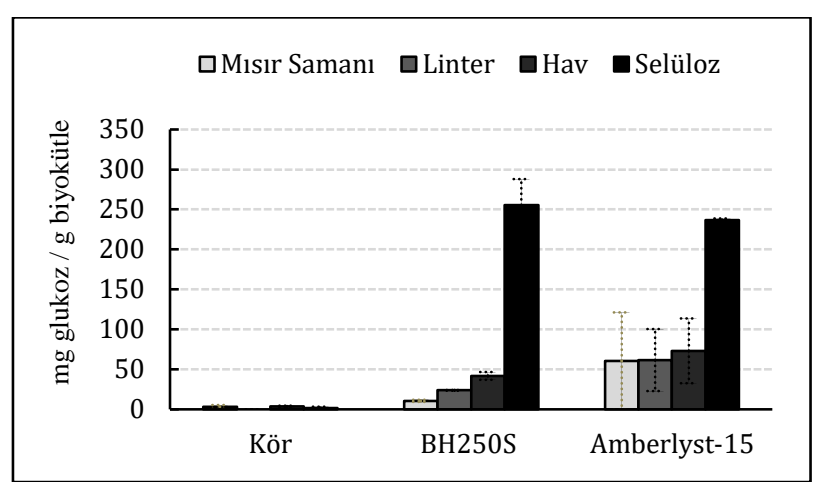

Şekil 6. Dönüşüm deneyleri sonrası çözeltide kalan glikoz miktarlarının kıyaslanması

Sonuçlara bakıldığında özellikle mikrokristalin selüloz katalizör yardımıyla glikoz monomerlerine daha fazla parçalanmış ve 5-HMF'ye dönüşmeyen fazlaca bir kısım çözelti ortamında kalmıştır. BH250S katalizörünün 5-HMF dönüșüm aktivitesi ticari katalizör Amberlyst-15 kıyasla daha iyi olduğundan reaksiyon sonrası ortamda genel olarak daha az glikoz molekülü bulunmaktadır.

\section{Tartışma ve Sonuç}

Biyokütle türevli karbon bazlı sülfolanmış katı asit katalizörler literatürde özellikle selülozun hidrolizinde yüksek katalitik aktiviteleri, tekrar kullanılabilir olmaları, ucuz ve doğal hammadde kaynaklarından hazırlanmaları nedeniyle son yıllarda oldukça ilgi çekmektedir. Bu çalışmada buğday samanı ilk kez karbon katalizörler için başlangıç materyali olarak kullanılmış ve daha önce hiç çalışılmamış olan linter ve hav gibi farklı atık biyokütlelerin bu katalizör ile sulu ortamda 5-HMF'ye dönüşüm verimleri incelenmiștir. Mısır samanı, hav ve mikrokristalin selüloz dönüşümlerinde en iyi sonuçlar BH250S katalizörü ile elde edilmiş, atık havdan bu katalizör ile gram biyokütle bașına 12,5 mg 5-HMF elde edilirken, buna karşllık ticari katalizör Amberlyst-15 dönüşüm aktivitesi göstermemiştir. Model bileşik saf mikrokristalin selülozun 5-HMF dönüşümü katalizörsüz ortama kıyasla yaklașık 3 katlık artıș göstermiștir.

Literatürde yer alan benzer bir çalışmada hidrotermal karbonizasyon ile misır sapından elde edilen sülfolanmış karbon katı asit katalizör ile iyonik sıvı ortamında çalışılmış, iyonik sıvının hem çözücü hem katalizör etkisinden faydalanılarak daha yüksek 5-HMF dönüșüm verimi elde edilmiștir [17]. Ancak iyonik sıvının toksik etkileri göz önünde bulundurulduğunda, çözücü olarak suyun tercih edilmesi ve verimi arttırmak için katalizörün modifikasyon ile geliştirilmesi daha çevreci bir yaklaşım olacaktır. Çalışmanın devamında bu karbon katalizöre daha fazla asidik özellik kazandırabilecek farklı fonksiyonel gruplar bağlanarak biyokütle hidrolizi ve değerli kimyasal eldesi konusunda endüstriyel düzeyde çalıșmalar gerçekleștirilebilir.

\section{Tessekkür}

$\mathrm{Bu}$ çalışmanın gerçekleşmesindeki desteklerinden dolayı Bursa Teknik Üniversitesi BAP (171N09 nolu proje) birimine teşekkür ederiz.

\section{Kaynakça}

[1] Mukherjee, A., Dumont, M-J., Raghavan, V. 2015. Review: Sustainable production of hydroxymethylfurfural and levulinic acid: Challenges and opportunities. Biomass and Bioenergy, 72, 143-183.

[2] Dutta, S., De, S., Alam, M., Abu-Omar, M. M., Saha, B., 2012. Direct conversion of cellulose and lignocellulosic biomass into chemicalsand biofuel with metal chloride catalysts. Journal of Catalysis, 288, 8-15.

[3] Rathod, P. V. and Jadhav V. H., 2018. Efficient Method for Synthesis of 2,5-Furandicarboxylic Acid from 5-Hydroxymethylfurfural and Fructose Using Pd/CC Catalyst under Aqueous Conditions. ACS Sustainable Chemistry and Engineering, 6, 5766-5771.

[4] Chang, C., $\mathrm{Xu}_{2}$ G., Jiang $\mathrm{X}_{\text {., }}$ 2012. Production of ethyl levulinate by direct conversion of wheat straw in ethanol media. Bioresource Technology, 121, 93-99.

[5] Dutta, S., Yu, I. K. M., Tsang, D. C. W., Ng, Y. H., Ok, Y. S., Sherwood, J., Clark, J. H., 2019. Green synthesis of gamma-valerolactone

(GVL) 
through hydrogenation of biomass-derived levulinic acid using non-noble metal catalysts: A critical review. Chemical Engineering Journal, 372, 992-1006.

[6] Fukuhara, K., Nakajima, K., Kitano, M., Kato, H., Hayashi, S., Hara, M. 2011. Structure and catalysis of cellulose-derived amorphous carbon bearing $\mathrm{SO}_{3} \mathrm{H}$ groups. Chemsuschem, 4:778-784.

[7] Hara, M. 2010. Biomass conversion by a solid acid catalyst. Energy \& Environmental Science, 3:601-607.

[8] Uskan, B. 2009. Odun Talașının Hidrotermal Dönüşümünden Elde Edilen Kimyasalların Karakterizasyonu. Ankara Üniversitesi, Fen Bilimleri Enstitüsü, Yüksek Lisans Tezi, 109s, Ankara.

[9] ASTM, 2009. Standard Test Method for Determination of Acid-Insoluble Residue in Biomass, Pennsylvania United States: ASTM

[10] Foyle, T., Jennings, L., Mulcahy, P. 2007. Compositional analysis of lignocellulosic materials: Evaluation of methods used for sugar analysis of waste paper and straw. Bioresource Technology, 98, 3026-3036.

[11] Sun, R. C., Tomkınson, J. 2002. Characterizations of hemicelluloses obtained by classical and ultrasonically assisted extractions from wheat straw. Carbohydrate Polymers, 50, 263-271.
[12] Gan, L., Zhu, J., Lv, L. 2017. Cellulose hydrolysis catalyzed by highly acidic ligninderived carbonaceous catalyst synthesized via hydrothermal carbonization. Cellulose, 24, 5327-5339.

[13] Suganuma, S., Nakajima, K., Kitano, M., Yamaguchi, D., Kato, H., Hayashi, S., Hara, M. 2008. Hydrolysis of Cellulose by Amorphous Carbon Bearing $\mathrm{SO}_{3} \mathrm{H}, \mathrm{COOH}$, and $\mathrm{OH}$ Groups. Journal of American Chemical Society, 130, 12787-12793.

[14] Wu, Y., Fu, Z.,Yin, D., Xu, Q., Liu, F., Lu, C., Mao, L. 2010. Microwave-assisted hydrolysis of crystalline cellulose catalyzed by biomass Char sulfonic acids. Green Chemistry,12, 696-700.

[15] Irmak, S., Meryemoglu, B., Sandip, A., Subbiah, J., Mitchell, R. B., Sarath, G. 2018. Microwave pretreatment effects on switchgrass and miscanthussolubilization in subcritical water and hydrolysate utilization for hydrogen production. Biomass and Bioenergy, 108, 48-54.

[16] Huang Y-B. ve Fu Y. 2013. Hydrolysis of cellulose to glucose by solid acid catalysts. Green Chemistry, 15, 1095-1111.

[17] Yan, L., Liu, N., Wang, Y., Machida, H., \& Qi, X. 2014. Production of 5-hydroxymethylfurfural from corn stalk catalyzed by corn stalk-derived carbonaceous solid acid catalyst. Bioresource Technology, 173, 462-466. 